\title{
A rare case of broad ligament hematoma masquerading ovarian malignancy in a post-menopausal woman: a case report
}

\author{
Sunita Verma, Binni Makkar*, Poonam Singh, Netra Singh
}

Department of Obstetrics and Gynaecology, Fortis Hospital, Shalimar Bagh, New Delhi, India

Received: 22 November 2016

Accepted: 13 December 2016

\author{
*Correspondence: \\ Dr. Binni Makkar, \\ E-mail: binnimkkr@gmail.com
}

Copyright: () the author(s), publisher and licensee Medip Academy. This is an open-access article distributed under the terms of the Creative Commons Attribution Non-Commercial License, which permits unrestricted non-commercial use, distribution, and reproduction in any medium, provided the original work is properly cited.

\begin{abstract}
Spontaneous broad ligament hematomas are relatively rare in non- pregnant state. We hereby present a case report of a 73 year old post-menopausal female, who initially presented with complain of postmenopausal bleeding since 4 month. Patient had underwent a diagnostic endometrial curettage in an another hospital, prior to presenting to our institution. On imaging, she was found to have a right sided complex adenexal mass (about $5 \mathrm{~cm}$ in size) suspicious of ovarian malignancy. Patient was taken up for exploratory laparotomy and per-operatively found to have a broad ligament hematoma, which was further confirmed on histopathological examination.
\end{abstract}

Keywords: Broad ligament hematoma, Ovarian malignancy, Post-menopausal

\section{INTRODUCTION}

Spontaneous broad ligament hematomas are rare especially during non- pregnant state. These may be seen in association with pregnancy, trauma or surgical intervention. ${ }^{1,2} \mathrm{We}$, hereby, report an unusual case of a broad ligament hematoma in a post- menopausal woman following a minor surgical intervention.

\section{CASE REPORT}

A 73 year old multiparous lady, menopausal since 25 years, presented in routine OPD with complain of postmenopausal bleeding on and off since 4 months. Patient had consulted another gynaecologist prior to coming to us. There, she underwent fractional curettage and the histopathological report was suggestive of endometrial atrophy. There were no other significant gynaecological complaints. Regarding her medical comorbidities, she had been a known case of chronic hypertension, controlled on treatment. There was no other significant past medical or surgical history. On examination, her vitals were stable and the general physical examination was unremarkable. In addition, her per- abdominal examination was also unremarkable with no evidence of any tenderness or an obvious palpable mass. On per speculum examination, cervix appeared healthy with no evidence of active bleeding through os. On per vaginum examination, uterus was retroverted small size and there was a vague fullness in left fornix. Patient was investigated on out-patient basis. Investigations done included complete blood count, liver function test, renal function test, blood sugars, CA-125 levels, CEA and urine routine examination. Her CA-125 levels and CEA levels were 8IU/dl and 3.0IU/dl respectively.

Other blood and urine tests were normal. In addition, she underwent transvaginal sonography, which revealed a normal sized uterus with presence of a lobulated heterogeneous mass in right adenexa adjoining the right lateral wall of uterus. However, an ultra sonogram done 2 months earlier (prior to the diagnostic curettage) was unremarkable. Patient further underwent MRI pelvis which confirmed the presence of a irregular lobulated heterogeneous mass in the right adenexa (about $5 * 5 \mathrm{~cm}$ ) with multiple septations seen within (Figure 1). The right ovary was not seen separately from the mass. In addition, 
uterus appeared normal size and left adenexa was normal. In view of her menopausal status and presence of a moderate sized complex adenexal mass, patient was planned for laprotomy. Patient was subsequently admitted and operated. During laprotomy, a complex solid-cystic mass was seen in the broad ligament on the right side, along the lateral side of uterine wall extending up to the upper vagina. This mass was excised (after opening the leaves of broad ligament) and sent for frozen section which confirmed presence of a benign hemorrhagic cyst with band like siderophages suggestive of an old hematoma (Figure 2). Uterus and bilateral ovaries were unremarkable and these were also removed during the surgery.

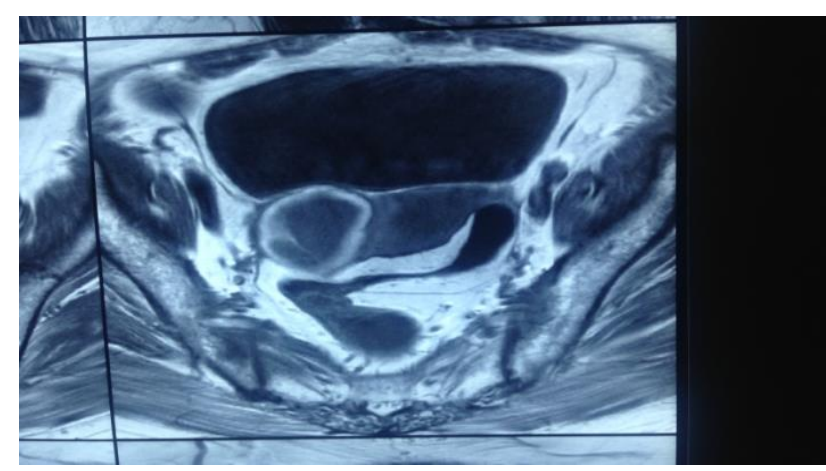

Figure 1: MRI image of the patient showing complex adenexal mass on right side.

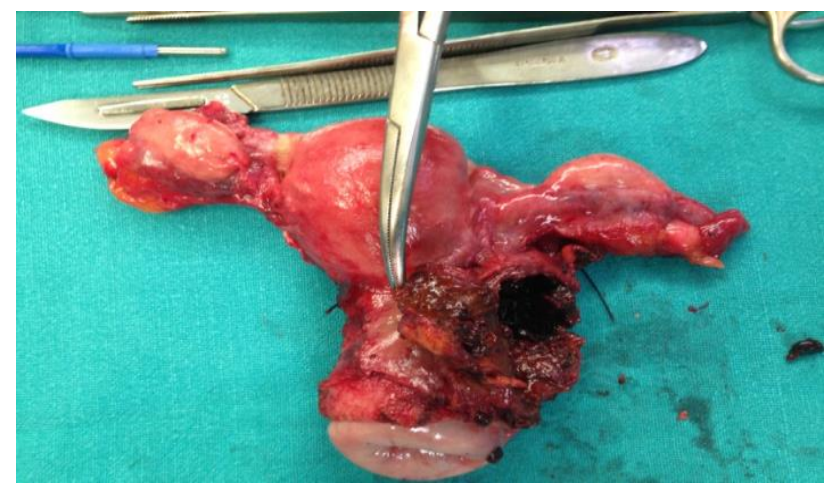

Figure 2: Specimen showing uterus with broad ligament hematoma (evacuated) on right side.

\section{DISCUSSION}

Broad ligament hematomas may be seen in association with pregnancy, trauma or surgical intervention. ${ }^{1-3}$ These are seen more frequently in association with pregnancy. During pregnancy, these may be seen as a result of ruptured ectopic pregnancy, a complicated vaginal delivery or in patients with previous caesarean section in labour due to scar rupture. Spontaneous broad ligament hematomas have been reported in patients with known coagulation/bleeding disorders during non-pregnant state. ${ }^{4}$ Duckett et al reported a case of broad ligament hematoma in a non-pregnant female, in association with a large uterine fibroid. ${ }^{5}$ Hematoma had developed while the patient was mowing her lawn. It was suggested to be caused by venous injury caused due to raised intraabdominal pressure in association with presence of the uterine fibroid and increased exertion caused by mowing the lawn. In non- pregnant state, broad ligament hematomas may occur in association with ruptured endometriosis cyst, transvaginal retrieval of oocytes or following snake bite. ${ }^{6,7}$

In our patient, hematoma appears to be caused by the trauma due to diagnostic curettage which the patient had undergone prior to her presentation to our centre. A normal pelvic scan prior to the curettage further supports this postulation. In addition, there was no history/lab evidence of any coagulation disorder in our patient.

In our patient, one may note that there were no symptoms like acute pelvic pain, back pain or any other pressure symptoms. This might be due to the slow development and self limiting nature of hematoma in this case. In contrast, rapidly growing hematomas usually present with features of acute abdomen and hemodynamic instability.

Broad ligament hematoma may closely mimic an ovarian/adenexal mass and sometimes may not be differentiated from the latter even on imaging modalities like MRI, as was seen in our case. In such cases, laprotomy/laparoscopy may be the only means to confirm the diagnosis and for definite management. In our patient, a diagnostic laparoscopy could also have been done, however laprotomy was planned keeping in mind her menopausal status and high suspicion of ovarianmalignancy, after consultation with onco surgeon. Formation of broad ligament hematoma following fractional curettage, in non pregnant case, has not been reported so far in the literature.

\section{CONCLUSION}

To conclude, although broad ligament hematoma is a very rare complication of fractional curettage, one must keep in mind possibility of such diagnosis in similar clinical scenarios.

Funding: No funding sources Conflict of interest: None declared Ethical approval: Not required

\section{REFERENCES}

1. Muthulakshmi B, Francis I, Magos A, Roy M, Watkinson A. Broad ligament haematoma after a normal delivery. J Obstet Gynaecol. 2003;23(6):66970 .

2. Parulekar SV. Post-hysterectomy broad ligament haematoma: a complication of vaginal packing? (A case report). J Postgrad Med. 1989;35(1):51-3.

3. Kemp J, Cooper R, Robertson R. Vault haematoma after vaginal hysterectomy: an invariable sequel. Aust N Z J Obstet Gynaecol. 1986;26(4):317. 
4. Greer IA, Lowe GD, Walker JJ, Forbes CD. Haemorrhagic problems in obstetrics and gynaecology in patients with congenital coagulopathies. $\mathrm{Br} \quad \mathrm{J}$ Obstet Gynaecol. 1991;98(9):909-18.

5. Duckett RA, Pillai M, Marsh L. A case of spontaneous broad ligament haematoma. J Obstet Gynaecol. 2007;27(4):448-49.

6. Tureck RW, García CR, Blasco L, Mastroianni L Jr. Perioperative complications arising after transvaginal oocyte retrieval. Obstet Gynecol. 1993;81(4):590-3.
7. Addo V, Kokroe FA, Reindorf RL. Broad ligament haematoma following a snake bite. Ghana Med J. 2009;43(4):181-2.

Cite this article as: Verma S, Makkar B, Singh P, Singh N. A rare case of broad ligament hematoma masquerading ovarian malignancy in a postmenopausal woman: a case report. Int J Reprod Contracept Obstet Gynecol 2017;6:746-8. 